\title{
The Coming of Age of Long-distance Wireless Telegraphy and some of its Scientific Problems. ${ }^{1}$
}

$T^{T}$ is just twenty-one years since Senatore Marconi 1 began to equip with wireless apparatus a station at Poldhu in Cornwall for the first attempt at transatlantic wireless telegraphy. Until then only appliances of a laboratory. type had been used to signal to distances of about 100 miles. This first attempt at long-distance working necessitated the conversion of these appliances into engineering plant employing large power. Although at first the spark system, in which the electric waves are generated by discharges of large electric condensers, was used at Clifden in Ireland and Glace Bay in Nova Scotia, and developed by Senatore Marconi ultimately into the timed spark continuous wave system in the great wireless stations at Carnarvon, N. Wales, New Jersey, U.S.A., and Stavanger, Norway, the usual practice of late years has been to employ either the Poulsen electric arc generator, the high-frequency alternator, or, more recently, the thermionic valve generator. At the recently projected gigantic wireless stations, such as those at St. Assise, near Paris, and Long Island, U.S.A., the high-frequency alternators of LatourBathenod and of Alexanderson are to be employed. At the first Imperial wireless station at Leafield, Oxfordshire, erected by the General Post Office to correspond with one at Cairo, the Elwell-Poulsen arc generator is used. The arc generator has, however, the disadvantage that the waves emitted are a mixture of wave-lengths, and not a single pure wave or monochromatic. Important installations of large valve transmitters have recently been made by the Marconi Wireless Telegraph Company at Clifden, Ireland, and at their great Carnarvon station in N. Wales.

The length of waves mostly used for long-distance radio work is between 10,000 and 20,000 metres, or about 6 to 12 miles. It is possible from all large radio stations at the present time to communicate with their antipodes. So far as reception is concerned this long-distance working is entirely due to the thermionic valve, the first type of which was invented by Prof. Fleming in 1904.

It has been proved by the labours of many eminent

1 Abridged from the fifth Henry Trueman Wood lecture at the Royal Society of Arts, delivered on Wednesday, November 23, by Prof. J. A. leming. mathematicians during the last twenty years, how ever, that the received signals at distances of 6000 to $\mathbf{1 2 , 0 0 0}$ miles are many thousands or even millions of times stronger than can be accounted for by pure diffraction or bending of the waves round the earth, and it is now fairly generally agreed that long-distance wireless telegraphy takes place only in consequence of the existence of an electrical conducting layer in the earth's atmosphere at a height probably of from Ioo to 200 kilometres.

The presence of this highly conductive layer in the upper regions of the atmosphere, in which the component gases are hydrogen and helium, is probably due to electrified dust which comes to us from the sun being powerfully repelled against the attraction of gravitation by the pressure due to waves of light. This dust comes from the sun with enormous velocity and enters the higher levels of the atmosphere, render. ing it an electric conductor. The conducting layer guides the radio waves round the earth and prevents them from escaping into space.

In addition, sunlight ionises the subjacent region during the day, but this is removed during the night. Vagrant natural electric waves are always being produced in the atmosphere, and are called "strays", they are a serious nuisance in radio signalling at certain times, and especially in the tropics. The great outstanding problem of long-distance wireless telegraphy and telephony is the neutralisation of the effect of these vagrant waves on the receiving apparatus.

Prof. Fleming concluded with some remarks on the bearing on the theory of wireless telegraphy of recent physico-mathematical speculations on relativity, and especially the agnostic view now taken as regards the existence of a space-filling æther. It is clear that space is not a mere vacuum, but has remarkable powers of storing and transmitting energy, but modern physical and astronomical discoveries have rendered necessary great modification in our ideas regarding the structure of space or the æther, and no theory of radiation has yet been propounded which explains satisfactorily all the known facts. We are as yet unable to give any wholly satisfactory explanation as to the nature of the waves used in wireless telegraphy.

\section{Physical Science at the British Association.}

\begin{abstract}
UDGING by the continued interest displayed in $\int$ the meetings of Section A during the recent visit of the British Association to Edinburgh, the prom ceedings of this section may be accurately described as very successful. Four strenuous mornings were devoted to the formal work of the section, yet the meeting-place was frequently overciowded, and, even at the very end of the session, the audience numbered about eighty. There can be no doubt that the poicy of the Association in encouraging joint discussions between the sections has met with general approval. Section A participated in two of these, both proving of absorbing interest. It is true that the time occupied by the joint meetings put a severe strain upon the rest of the sectional programme, which was undoubtedly too large, consisting of no fewer than twenty-nine items. This led to the necessity of adopting the somewhat undesirable practice of splitting up frequently into sub-sections; and the question of the limitation of the programme in future years is well worthy of consideration.
\end{abstract}

Some new departures were made by Section $\mathrm{A}$ at the Edinburgh meeting. The afternoon of the first day was made the occasion for demonstrations of novel physical experiments in the laboratories of the Natural Philosophy Department, where also apparatus of historical interest was exhibited. A semi-popular lecture was delivered on another atternoon. Both these new activities of the section met with great success, and ought certainly to be repeated at subsequent meetings. It may be hoped, too, that the excellent arrangements for producing a daily weather report (referred to later) will become a normal part of the work of Section A.

From remarks made earlier in reference to the lengthy programme, it will be understood that in the present report little more can be done than give a list of the papers and authors, with the addition of a few descriptive remarks in cases of outstanding interest. The proceedings opened on the morning of September 8 with a paper by Prof. J. C. McLennan on "Radiation and Absorption by Atoms with 